\title{
Validation of indwelling vaginal sensor to monitor body temperature in ewes
}

\author{
Bobbie E. Lewis Baida ${ }^{1 *}$, Mathias Baumert ${ }^{2}$, Alok Kushwaha², Alyce M. Swinbourne ${ }^{3}$, Stephan T. Leu ${ }^{1}$ (i) and \\ William H. E. J. van Wettere ${ }^{1}$ (1)
}

\begin{abstract}
Remote-sensing technology facilitates longitudinal collection of body temperature during periods of hot or cold environmental stress without human interference, producing high-frequency measurements whilst reducing labour and stress to the animal. A pilot study was conducted to validate an improved, minimally invasive method for the continual measurement of vaginal temperature (VT) in female sheep. A silicon mould of a modified controlled internal drug release (CIDR) device (Zoetis Animal Health, Parsippany), was manufactured to securely house a temperature logger (Micro-T 16-bit; Star Oddi, Iceland) and allow direct contact at the collection site. These temperature-sensing CIDR devices were validated against manual rectal temperature (RT) measurements collected from 15 mature, nonpregnant, non-lactating Merino ewes. Rectal temperature was measured from each individual, six times per day in 2-h intervals for 14 consecutive days. The simultaneous measures of VT and RT did not differ significantly within each ewe $(P>0.05)$ and demonstrated a moderate linear relationship $\left(R^{2}=0.62, P<0.05\right)$. The mean $( \pm$ SEM) difference between RT and VT was small $\left(0.010 \pm 0.004^{\circ} \mathrm{C}\right)$, with a $95 \%$ confidence interval of -0.26 to $0.29^{\circ} \mathrm{C}$. Additionally, the coefficient of variation was lower on average for VT (0.49\%) compared to RT (0.59\%). Differences among paired readings were likely due to interval variation as well as penetration depth, air influx and faecal temperature when collecting RT. The initial silicone manufacturing costs were high (2200 AUD), with each unit costing 1.25 (AUD) thereafter; however, the temperature-sensing CIDR device was an effective and efficient research tool for the remote monitoring of body temperature. While further validation of these devices within extensive grazing environments is warranted, the collection and analysis of longitudinal physiological data from ewes has the potential to improve a variety of management aspects related to extensively grazed ewes maintained and joined in harsh conditions.
\end{abstract}

Keywords: Sheep, Telemetry, Indwelling temperature probe, Vaginal temperature monitoring, Core temperature, Physiology, Stress-induced hyperthermia

\section{Introduction}

Climate change is the most serious environmental challenge faced by producers around the world, threatening the physiology, reproductive function and overall health and productivity of livestock [1]. Heat stress often occurs when the effective environmental temperature exceeds

\footnotetext{
*Correspondence: bobbie.lewisbaida@adelaide.edu.au

${ }^{1}$ Davies Livestock Research Centre, School of Animal and Veterinary

Sciences, The University of Adelaide, Roseworthy Campus, Mudla Wirra Rd, Roseworthy, SA 5371, Australia

Full list of author information is available at the end of the article
}

the upper critical temperature of a sheep $\left(25\right.$ to $\left.31{ }^{\circ} \mathrm{C}\right)$ [2], resulting in an imbalance between heat production within the body and its dissipation. Biologically, animals have the ability to minimise the negative effects of hot conditions by invoking physiological mechanisms [3], such as an increase in respiration rate and body temperature, as well as by adjusting their activity and feeding patterns to avoid hot periods of the day or increase the use of shaded areas [4]. An increase in core temperature is one of the primary physiological indicators and has been used to evaluate the heat stress response in sheep [5]. It is original author(s) and the source, provide a link to the Creative Commons licence, and indicate if changes were made. The images or other third party material in this article are included in the article's Creative Commons licence, unless indicated otherwise in a credit line to the material. If material is not included in the article's Creative Commons licence and your intended use is not permitted by statutory regulation or exceeds the permitted use, you will need to obtain permission directly from the copyright holder. To view a copy of this licence, visit http://creativecommons.org/licenses/by/4.0/. The Creative Commons Public Domain Dedication waiver (http://creativeco mmons.org/publicdomain/zero/1.0/) applies to the data made available in this article, unless otherwise stated in a credit line to the data. 
also related to a number of other varied functions such as activity, nutrition, health preservation and reproductive success [6, 7]. Manual measurement of temperature using a digital rectal thermometer is considered the best estimate of core body temperature and is currently the most reliable diagnostic tool for identifying illness [8], disease [9] or heat stress [5] in livestock animals. Rectal temperature (RT) is relatively accurate and repeatable; however, the presence of humans can often disrupt the behavioural and physiological responses of an animal and lead to stress-induced hyperthermia [10]. Additionally, manual thermometry is labour intensive and only provides a cross-sectional sample due to the need to handle and restrain the animal. For this reason, manual thermometry is not suitable for the longitudinal assessment of body temperature patterns in free-ranging animals [11]. To circumvent the issues associated with manual collection, a plethora of automated technologies are being trialled for the continuous, remote measurement of body temperature in livestock animals [12].

Technologies appropriate for the automated collection of heat stress data in sheep have been recently reviewed [13]. Many tools used to measure core temperature, such as subcutaneous microchips or rumen boluses, require surgical intervention or are otherwise invasive $[14,15]$. These methods are also not always practical in a research setting due to their irretrievability or fatal outcome for the animals, and orally administered rumen sensors are affected by internal environmental changes, such as drinking events [16]. A non-invasive, contactless approach is the use of thermal imaging or infrared thermography (IRT). Despite being a relatively useful tool for monitoring body temperature in sheep [17], skin or peripheral temperature can vary depending on the presence or absence of wool and readings can be affected by ambient temperature and UV light, leading to inconsistencies at different anatomical locations $[18,19]$. Another less invasive and more practical method is the use of indwelling temperature probes [20-22]. Despite consistently recording core temperature in livestock species, rectal probes require external physical attachment to secure the device and resist expulsion during defecation [13, 19]. Although this has been achieved in cattle with the use of a tail harness [23], a reliable attachment method has yet to be developed in sheep, which typically lack a comparable tail. Difficulties in keeping the temperature probe stationary as well as expulsion and faecal temperature during defecation therefore limit the practicality and reliability of this method in sheep. These limitations have led to the collection of vaginal temperature (VT) and the use of indwelling vaginal probes in female sheep [24], as differences in VT and RT have been found to be negligible when using identical temperature measuring devices
[25]. Affordability, practicality and welfare concerns can affect how body temperature is measured, including the frequency of measurement as well as the type of device which is used. In addition to comparing the measurement of body temperature at different anatomical locations, different types of temperature loggers have also been compared by measuring VT with two sensor types simultaneously within the same animal [26].

The most common deployment technique for inserting temperature loggers into the vagina is the use of controlled internal drug release (CIDR) devices. Usually containing progesterone to synchronise oestrous, these devices are instead sourced as blanks (i.e. no hormonal treatment) and used to house a self-contained temperature logger. The same technique has been used in both sheep [21] and cattle [27], whereby a segment of the CIDR was removed, replaced with a temperature-sensing device and secured in place with tape or shrink tubing. Despite previous studies reporting the relative effectiveness of this method [21, 22, 27], temperature sensor coatings such as tape and/or shrink tubing can influence body temperature measurements. As most temperature sensors used to study thermoregulation are coated with a suitable material to waterproof the device as well as to protect the animal from infection [28], extra coatings applied to secure the device in place can influence accuracy and response time for core temperature data collection. Due to huge variability in tag design, deployment methods and animal physiology, it is not possible to make a general quantification on the effect of sensor coatings on body temperature measurements. However, the materials used to coat the devices are known to thermally insulate the sensor, potentially biasing temperature measurements and indicating an improved thermoregulatory response than what actually exists [28]. Here, we present an alternative method for deploying an indwelling vaginal temperature sensor in Merino ewes in order to eliminate the risk of bias associated with additional material layers or coatings. This newly engineered deployment design allows direct contact between the temperature sensor and the skin inside the vagina, giving the sensor the ability to accurately capture acute fluctuations in core temperature. As a result, this study successfully validated an improved deployment method by evaluating the relationship between manual rectal temperature and automated vaginal temperature in Merino ewes.

\section{Materials and methods \\ Animals}

This was a collaborative experiment between The University of Adelaide and South Australian Research and Development Institute (SARDI), and conducted in latesummer, February 2021 at the Turretfield Research 
Centre, Rosedale, South Australia ( $\left.34^{\circ} 33^{\prime} \mathrm{S}, 138^{\circ} 50^{\prime} \mathrm{E}\right)$. All animal use, housing and methodology were approved by the PIRSA Animal Ethics Committee (project: 11/12) and conducted in accordance with the provisions of the Australian Code for the Care and Use of Animals for Scientific Purposes.

Both RT and VT data were collected from fifteen 4-year-old South Australian dry (non-pregnant, nonlactating) Merino ewes (Ovis aries) $(75.8 \pm 1.6 \mathrm{~kg}$ body weight). VT was collected using a newly developed indwelling vaginal probe, whilst RT was collected manually using a high-accuracy digital thermometer. Ewes were randomly selected, moved from the paddock and split into two outdoor yards $\left(10 \mathrm{~m}^{2}\right.$; pen $1, n=8$; pen 2 , $n=7$ ), for a 6 -day acclimatisation period. Ewes were then moved to an indoor facility and randomly housed in individual pens $(2.5 \times 1.5 \mathrm{~m})$ for the remainder of the study (14 days). VT sensors were inserted into the ewes upon moving into the indoor facility and ewe temperature data were collected at 10-min intervals. Restraint of ewes by experienced personnel in a pen or raceway was required to instal the device, taking less than 1 min per ewe. As risk of irritation or infection increases as the length of deployment time increases, each ewe was inspected several times each day for irritation and/or device dislodgement. Signs of irritation/infection include excessive discharge, increased temperature and inappetence [29].

Between 0800 and $1800 \mathrm{~h}$ and $2 \mathrm{~h}$ apart, six RT data were manually collected, with exclusions at $0800 \mathrm{~h}$ on day 1 and $1400 \mathrm{~h}$ on day 8 which were accidentally missed and no data recorded. RT was collected by two trained personnel inserting a high-accuracy digital thermometer (One Step ${ }^{\circledR}$ ) approximately $5 \mathrm{~cm}$ into the rectum and pressing against the wall of the rectum until a stable reading was reached $(\sim 30 \mathrm{~s})$. Ambient temperature and relative humidity within the indoor housing facility was measured using a $\mathrm{HOBO}$ Temperature/Relative Humidity Data Logger (MX2302A; Onset Computer Corporation, USA), preprogramed to collect measurements every 10 min. During the study, ewes had ad libitum access to water and were fed $500 \mathrm{~g}$ of grain/ewe/day as well as rations of hay to ensure their energy requirement for maintenance was achieved.

\section{Device construction}

Modified CIDR devices and applicators were reverse engineered and moulded (AZ3D Pty Ltd.) using a combination of two manufacturing techniques: computer numerical control (CNC) machining and hydraulic press manufacturing. Initially, a P20 steel single cavity mould was created using CNC machining. Thereafter, hydraulic press manufacturing was used to produce 200 probes in a biocompatible silicon material with a shore hardness of 70. Design modifications were made to an original sheep CIDR device (Zoetis Animal Health, Parsippany, NJ), to enable the secure housing of a Star-Oddi Data Storage Tag (DST) (Micro-T 16-bit; Star-Oddi, Iceland) (Fig. 1). Modifications included adding curvature to the sharp edges of the probes to ensure the data logger was securely held in the cavity, along with increasing the diameter of the tail of the probe. Manufacturing cost of the silicone mould was 2200 AUD and following this, cost per unit was 1.25 AUD. The temperature loggers were placed inside the centre of each of the CIDR moulds, exposing the cylindrical sides of the logger and enabling direct contact between the logger and the skin inside the vagina (Fig. 1). These temperature sensors had an accuracy of $\pm 0.06{ }^{\circ} \mathrm{C}$ and were factory-calibrated and tested prior to receipt from the manufacturer. All loggers had a threepoint traceable calibration certificate at $10{ }^{\circ} \mathrm{C}, 25^{\circ} \mathrm{C}$ and $40{ }^{\circ} \mathrm{C}$, specifically calibrated for use at $5-45^{\circ} \mathrm{C}$. The logger was pre-programmed through a communication box

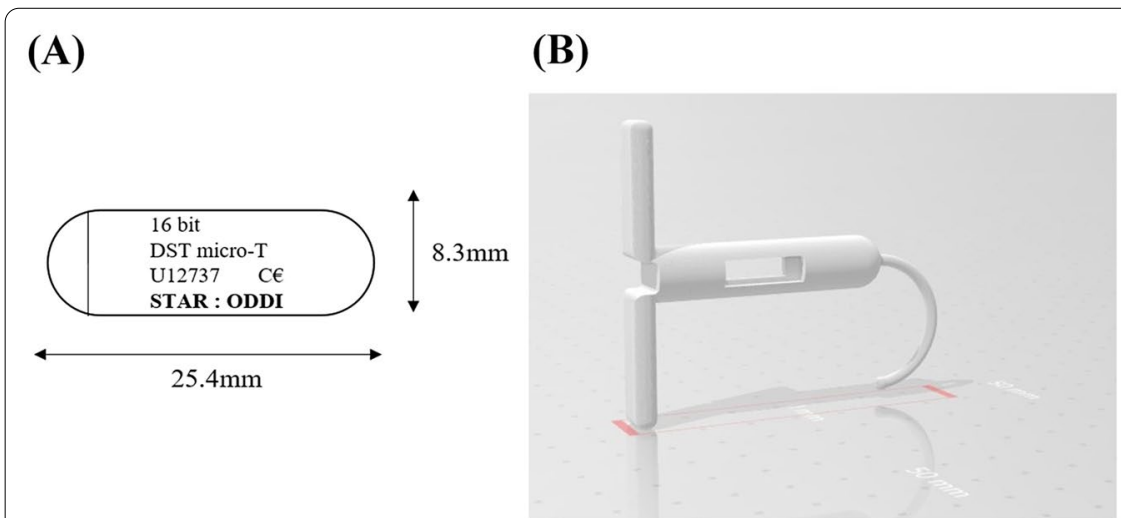

(C)

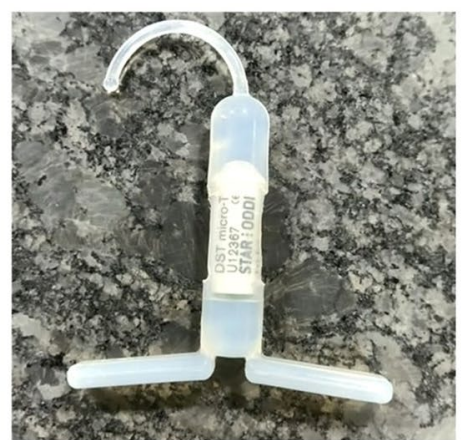

Fig. 1 A Size dimensions of Star-Oddi micro-T Data Storage Tag, B computerised prototype of CIDR mould and, C final product of CIDR replica containing temperature logger 
and Mercury software (Star Oddi, Iceland). Devices were inserted approximately $10 \mathrm{~cm}$ into the vagina of the ewes using a modified CIDR sheep applicator (Zoetis Animal Health, Parsippany, NJ) (Fig. 2), after applying Savlon ${ }^{\circledR}$ antiseptic cream to the tip of the applicator. At conclusion of the experiment, the devices were removed and data were downloaded with the communication box, exported to Microsoft Excel v. 2016 (Microsoft Corporation, Redmond, WA); and labelled with device/logger ID, ewe ID, date and time.

\section{Statistical analysis}

Statistical analysis was conducted using both IBM SPSS Statistics v. 26 and Xrealstats Statistics Package for Microsoft Excel v. 2016 (Microsoft Corporation, Redmond, WA). We excluded all VT data collected up to $1 \mathrm{~h}$ after insertion, as they were likely influenced by the insertion process. In order to compare VT and RT, we matched them with reference to animal ID and time-point. The manual RT data collection usually took $20 \mathrm{~min}$ and therefore, the mean VT based on the VT readings captured across this 20-min period was calculated. Automated VT and corresponding RT data were analysed using a linear regression to calculate the coefficient of determination. As the best anatomical location or methodology for determining an animals' true core temperature has yet to be defined, both VT and RT were estimated measures of core body temperature, and a relationship between these two measures was expected. As the coefficient of determination does not allow to determine the difference between measures, we also investigated the agreement between automated VT and manual RT using the Bland-Altman method [30]. We determined the strength of agreement, direction, and upper and lower agreement between VT and RT. To determine the concordance of VT against RT, a Pearson's and Lin's concordance correlations coefficients (LCCC) [31] were also conducted. Data are presented as means \pm standard error of the mean (SEM).

\section{Results and discussion}

The use of indwelling temperature sensors allowed for the automated measurement of VT at 10-min intervals in the absence of a human observer. The temperature sensors (DST Micro-T 16-bit; Star Oddi, Iceland), contain two centrally positioned thermistors and are coated in a highly thermally conductive ceramic material, which facilitated fast and uniform heat distribution throughout the whole device. Although relatively expensive, these loggers have the advantage over cheaper alternatives due to their high accuracy $\left( \pm 0.06{ }^{\circ} \mathrm{C}\right)$, sensitivity and rapid response time [26]. The replicas designed for this experiment eliminate the need for extra material to secure the loggers (shrink tubing, vinyl electrical tape, rubber, etc.), which has shown to create inconsistencies and decrease device sensitivity [28].

Considering the data logger as the experimental unit, $n=82$ paired observations per logger were generated and used to validate the temperature loggers in vivo. Mean $( \pm$ SEM) VT and RT at each time point were compared across the 14-day trial period to determine whether a similar pattern existed (Fig. 3). VT profiles of all animals remained relatively stable outside the manual data collection period; however, acute fluctuations in VT were consistently observed between 0800 and $1800 \mathrm{~h}$ each day which occurred during the period of manual RT collection. Although a precise explanation for these acute fluctuations cannot be elucidated, it is likely they were induced by human presence during manual data collection. Although domesticated, sheep are a prey animal and
(A)

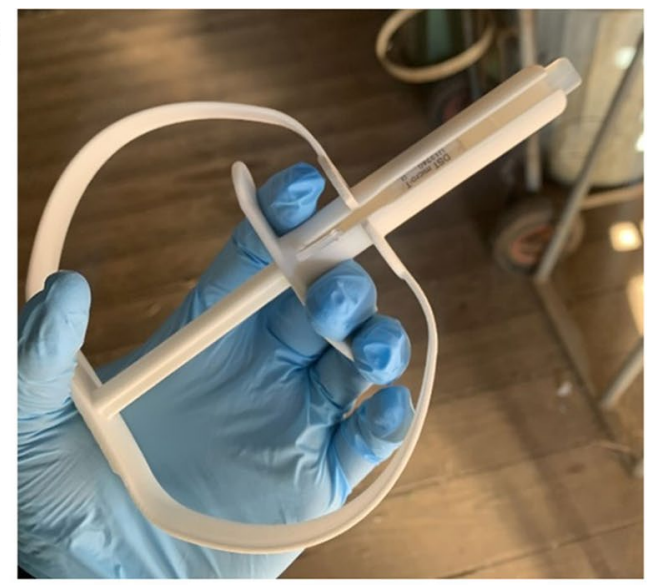

(B)

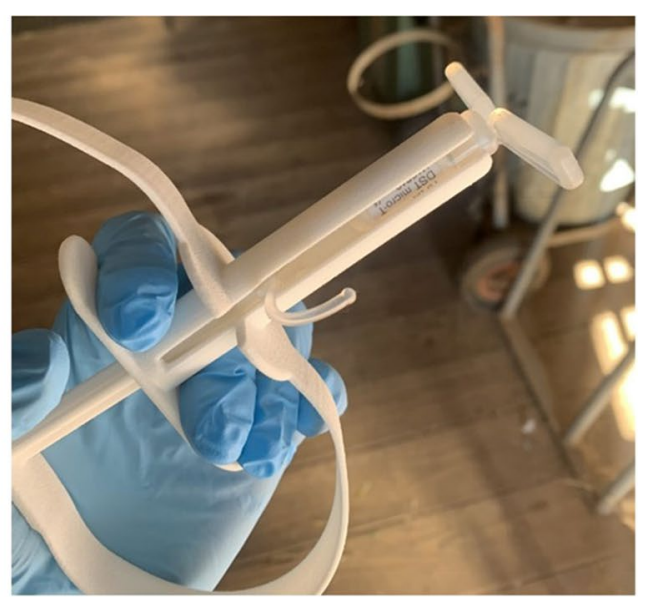

Fig. 2 A CIDR replica inserted into CIDR applicator and, B CIDR replica and logger ejected from applicator 


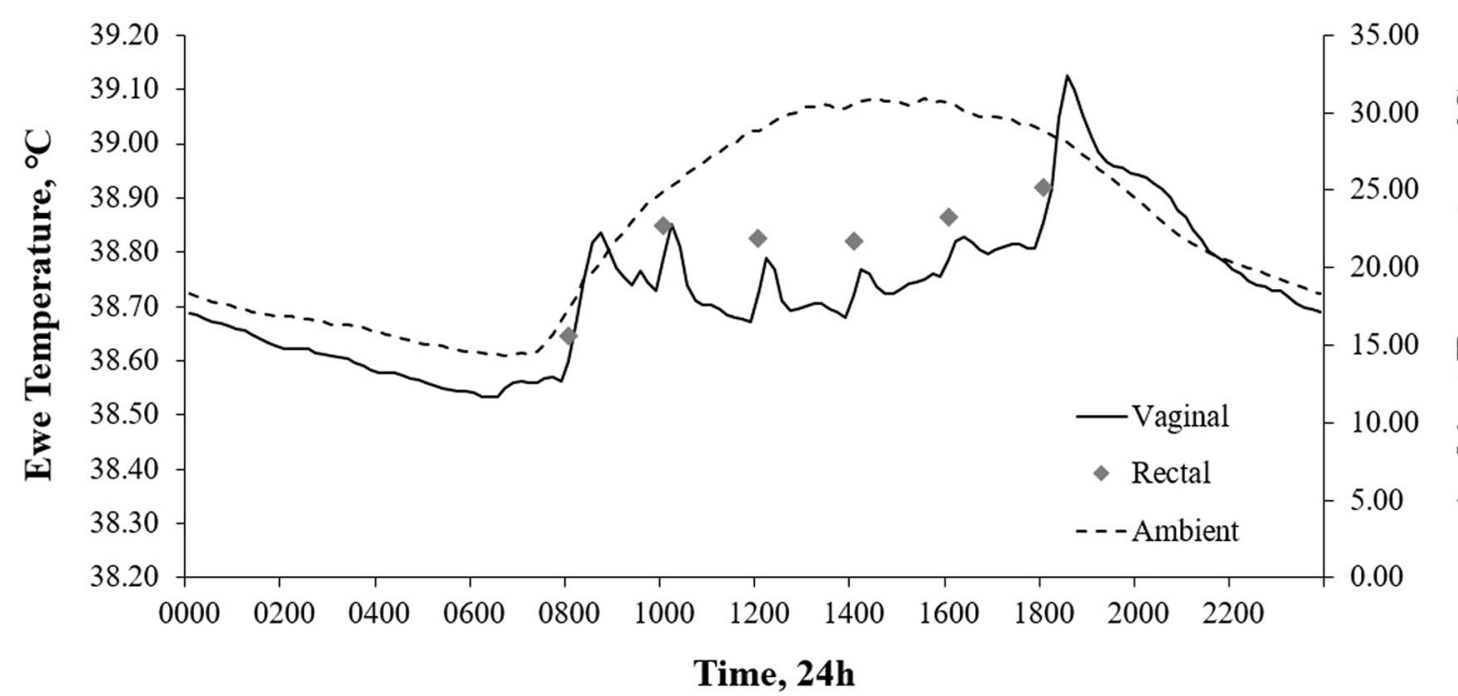

Fig. 3 Mean rectal, vaginal and ambient temperature measured across time. Pooled SEM: \pm 0.0106 and 0.0347 for vaginal and rectal, respectively

the behavioural responses of their wild ancestors evolved to evade detection and capture by predators [32]. For this reason, exposure to a stressor such as human handling can activate an endocrine response, leading to stressinduced hyperthermia ( $\mathrm{SIH}$ ) and increased metabolic heat production associated with the flight response [10]. Unlike studies which make direct comparisons between anatomical locations using the same, or varied automated technologies $[25,27,33]$, the current study compares the use of automated technologies versus manual measurement. Despite some using a similar approach in cattle $[20,34]$ and sheep $[15,20]$, researchers are yet to report how body temperature is influenced by the collection of RT. Following the manual collection of rectal temperature by researchers, an increase in mean ewe VT between 0.2 and $0.6{ }^{\circ} \mathrm{C}$ was observed at each collection time-point on each day, with the maximum increase recorded at $1800 \mathrm{~h}$ on day 10 of the trial period. Increases in VT were consistently seen to reach a peak at approximately $30 \mathrm{~min}$ after manual RT collection and before decreasing back to basal range. SIH in sheep is a common response to emotional or physiological stress, often caused by routine husbandry practices such as shearing [35] and transport [36]. When shearing was used to stimulate $\mathrm{SIH}$, it was found to last between 4 and 14 min post-shearing when automated body temperature was taken in 1-min intervals [35]. A higher collection interval in the current study would have allowed a more accurate measurement of the duration of SIH caused by human handling/restraint. Although diurnal variation across individual sheep is normal [37], acute core temperature changes of $\geq 0.5^{\circ} \mathrm{C}$ are considered a physiological response and in some cases, a welfare concern [38]. Increases in VT due to SIH seen here, are therefore biologically relevant and would introduce a level of interference if manual RT was used to quantify heat stress based on elevated core temperature. Hence, studies which have previously used manual RT as an indication of heat stress [39], may have biased results due to the influence of human interference and occurrence of SIH. Feeding occurred prior to data collection at both the $0800 \mathrm{~h}$ and $1800 \mathrm{~h}$ time points, which provides reasoning for a larger and extended increase in VT due to prolonged human presence at these time points. More research is necessary to truly define the influence of manual thermometry on core temperature fluctuations in sheep. Nevertheless, comparing each method simultaneously allows us to understand the relationship between varying techniques as well as anatomical localities.

The coefficient of determination indicated that there was a moderate linear relationship between VT and RT collected at the same time points $\left(R^{2}=0.62, P<0.0001\right.$; Fig. 4). The coefficient of variation was lower on average for VT $(0.49 \%)$ compared to RT $(0.59 \%)$, suggesting that there was less variation in VT in the current study; however, lower VT variation may be due to VT being averaged over three measures during the manual RT collection period. A previous study has also suggested that a strong relationship exists between manual RT and automated VT in lactating ewes after administration of lipopolysaccharide $(R=0.97, P<0.001$; [20]), as well as in lactating control ewes within the same experiment $(R=0.88, P<0.001 ;[20])$, and in gestating Senepol cows $(R=0.78, P<0.001$; [20]). Similarly, Vickers et al. [34] investigated the same relationship in dairy cows 


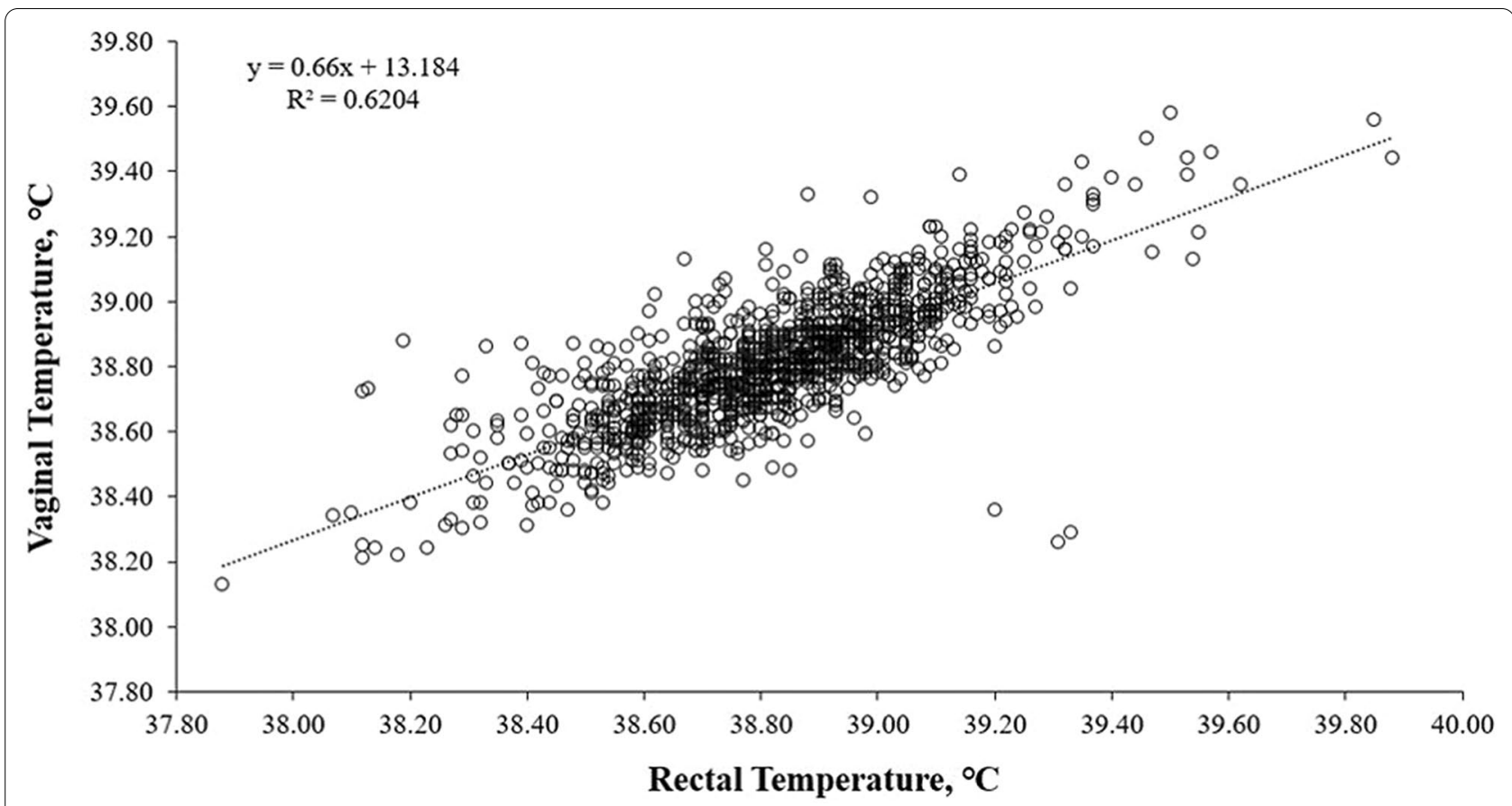

Fig. 4 Linear relationship between rectal temperature $\left(\mathrm{RT},{ }^{\circ} \mathrm{C}\right)$ and vaginal temperature $\left(\mathrm{VT},{ }^{\circ} \mathrm{C}\right)$ using data recorded at six, 2 -hourly time points across the 14-day trial period ( $n=82$ temperature measures per individual, 15 individuals)

postpartum $(R=0.81, P<0.001)$; however the strength of the relationship decreased by almost half during peak lactation $(R=0.46, P<0.001)$. The relationship identified within the current study $\left(R^{2}=0.62, P<0.0001\right)$ was lower than that previously described in sheep $(R=0.88$, $P<0.001$; [20]); however, different data collection and statistical methods were performed, making direct comparisons between the two studies difficult. Studies which compare the concurrent measurement of RT and VT using only automated temperature sensors tend to improve the relationship observed between the two anatomical locations $(R=0.92, P<0.0001 ;[27])$. Given that the current study used a combination of indwelling data loggers and a high accuracy hand-held thermometer to obtain time-point measurements, intervals were slightly variable. Additionally, when taking manual RT measurements, variations in penetration depth, air influx and faecal temperature could also contribute to differences encountered between RT and VT [34]. It is also important to consider the changes in uterine and vaginal blood flow which occurs at varying reproductive stages, which has been reported to alter VT in sheep [24, 40]. Regardless, the current study is the first to evaluate the relationship between VT and RT in dry Merino ewes using a novel deployment technique.

Calculating the correlation coefficient $(R)$ or coefficient of determination $\left(R^{2}\right)$ describes; (a) the relationship and direction between variables or, (b) the proportion of variance that two variables have in common, respectively [41]. Considering that RT and VT are both estimated measures of core body temperature, a close relationship between the two measures was anticipated. Therefore, results generated from the above models are sometimes inadequate and may be misleading, as a high correlation or linear relationship does not imply that there is strong agreement between two methods. An alternative method was introduced by Bland and Altman [30], which is used to quantify the agreement between two quantitative measurements by constructing limits of agreement [41]. Analysing RT and VT using the Bland-Altman approach $[30,42]$, ultimately determines whether two methods of measurement are comparable. As the body temperature of sheep is maintained within a tight range, $38.3-39.9^{\circ} \mathrm{C}$ [43], the Bland-Altman method of comparison was performed by using RT minus VT. In the current study, this model indicated that the mean difference between RT and VT was small $\left(0.010 \pm 0.004{ }^{\circ} \mathrm{C}\right)$, with a $95 \%$ confidence interval of -0.26 to $0.29^{\circ} \mathrm{C}$ (Fig. 5). Although the coefficient of variations suggests that automated measures of VT may be a more precise estimate of core body temperature in sheep, it is important to consider that VT was averaged over three measures during the manual RT collection period. Nevertheless, these results suggest that RT and VT are comparable and reproducible.

Secondary to the Bland-Altman method of comparison, measuring the reproducibility of a method from trial 

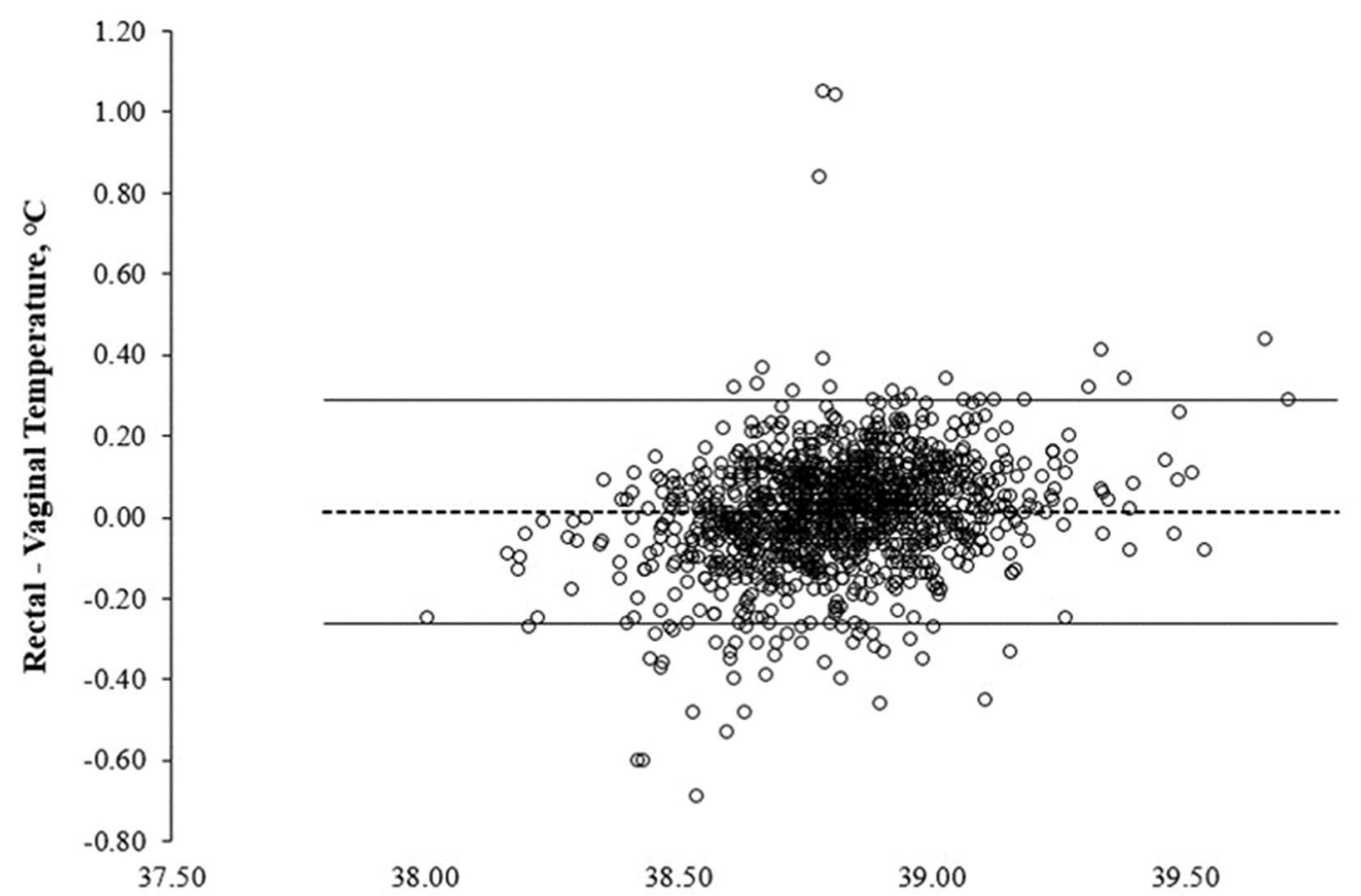

38.00

38.50

39.00

39.50

40.00

\section{Mean Temperature, ${ }^{\circ} \mathrm{C}$}

Fig. 5 Bland-Altman plot assessing the level of agreement between $\left(\mathrm{RT},{ }^{\circ} \mathrm{C}\right)$ and vaginal temperature $\left(\mathrm{VT},{ }^{\circ} \mathrm{C}\right)$ recorded at the same time point. Mean differences (dashed line) and confidence intervals $(95 \%=$ mean $\pm 1.96 \times \mathrm{SD}$; solid lines) are also indicated. The $x$-axis represents the mean temperature measurement as determined by averaging rectal temperature $\left(\mathrm{RT},{ }^{\circ} \mathrm{C}\right)$ and vaginal temperature $\left(\mathrm{VT},{ }^{\circ} \mathrm{C}\right)$, whilst the $y$-axis shows the difference in recorded temperatures for the two methods, in this instance RT-VT

to trial is also of interest. For this purpose, an index developed by Lin [31] which evaluates agreement between paired readings has advantages over other correlation models as it considers each measurement as a distinct reading rather than a replicate (random). The LCCC for the current study was 0.78 . Although there is little agreement and differences in stringency as to how to interpret LCCC values [44], values $\geq 1.0$ indicate strong concordance between two measures. Below this, LCCC is often interpreted similar to other correlation coefficients like Pearson's, where $<0.2$ is poor and $>0.8$ is excellent [45]. Others have a more rigorous interpretation, classing LCCC values $<0.9$ as poor [46]. Reasoning for such a high threshold is likely because LCCC usually gives a higher value for most practical situations [47]; however, this is often too high to be reasonable. The moderate LCCC value of 0.78 in this study is in agreement with the coefficient of determination $\left(R^{2}=0.62\right)$ and suggests a lowmoderate concordance or reproducibility of the methods, in alignment with the approach made by Altman [45] and others [48].

The body temperatures of mammalian species exhibit ultradian and circadian rhythms around a set point [49], which has shown to be influenced by climate [37].
When assessing the circadian rhythm in ruminants, body temperature is at its lowest in the morning and highest in the evening [50]. If body temperature is to be used to infer heat stress in free-ranging sheep, their daily temperature patterns need to be well understood. It is difficult to establish a definite circadian rhythm in the current study due to the interference during manual data collection. Nevertheless, a gradual decrease in vaginal temperature was consistently observed between 1900 and $0700 \mathrm{~h}$ the following day, with the highest temperatures occurring at approximately $1800 \mathrm{~h}$ (Fig. 3). In the absence of a human observer, the indwelling data loggers validated in this study would have the capacity to accurately assess the natural thermal rhythms in free-ranging sheep compared to manual collection using a hand-held thermometer. Similarly, due to the high-sensitivity of this technology, it has the potential to determine varying stages of the reproductive cycle in livestock. Changes in uterine and vaginal blood flow which occur at different stages of reproduction [40], have been shown to alter the VT of sheep during gestation as well increasing it during peak estrous [24]. Under consistent or controlled ambient conditions, these vaginal loggers have the capacity to 
better define how varying reproductive stages or hormonal activities throughout estrous can influence VT in ewes.

Weather conditions at the time of the experiment were relatively stable across the trial period. Although the experiment was conducted indoors, the facility was not temperature controlled and the sheep were therefore exposed to ambient conditions similar to those outside the housing facility. Ambient temperature

Table 1 Temperature data for each day during the trial period

\begin{tabular}{lllll}
\hline Day & Min. temp, ${ }^{\circ} \mathbf{C}$ & Max. temp, ${ }^{\circ} \mathbf{C}$ & Mean temp, ${ }^{\circ} \mathbf{C}$ & Max. $^{\text {THI }}{ }^{\mathbf{a}}$ \\
\hline 1 & 15.28 & 36.67 & $28.77 \pm 0.47$ & 83 \\
2 & 12.36 & 42.13 & $26.41 \pm 0.63$ & 84 \\
3 & 18.06 & 43.35 & $30.79 \pm 0.50$ & 85 \\
4 & 21.02 & 38.12 & $31.10 \pm 0.30$ & 81 \\
5 & 23.42 & 40.66 & $30.47 \pm 0.31$ & 83 \\
6 & 17.35 & 35.52 & $25.30 \pm 0.33$ & 80 \\
7 & 14.37 & 26.45 & $19.95 \pm 0.22$ & 72 \\
8 & 13.20 & 24.65 & $18.90 \pm 0.21$ & 70 \\
9 & 11.53 & 24.29 & $17.67 \pm 0.23$ & 69 \\
10 & 10.84 & 25.18 & $17.57 \pm 0.26$ & 70 \\
11 & 5.65 & 23.56 & $15.78 \pm 0.34$ & 69 \\
12 & 10.96 & 25.95 & $18.09 \pm 0.30$ & 71 \\
13 & 8.07 & 30.18 & $19.74 \pm 0.45$ & 75 \\
14 & 10.37 & 29.85 & $20.16 \pm 0.41$ & 75 \\
\hline
\end{tabular}

Minimum, maximum and mean ambient temperature, as well as the maximum temperature humidity index (THI). Mean values are represented as mean \pm SEM

${ }^{\mathrm{a}} \mathrm{TH}$ refers to the temperature humidity index calculated for each day by the following formula: $\mathrm{THI}=0.8 * T_{\mathrm{a}}+\mathrm{RH}\left(T_{\mathrm{a}}-14.4\right)+46.4$, where $T_{\mathrm{a}}=$ ambient temperature in ${ }^{\circ} \mathrm{C}$ and $\mathrm{RH}=$ relative humidity expressed as a proportion [5] measured inside the housing facility did not vary more than $2{ }^{\circ} \mathrm{C}$ from that recorded by the nearest, on-farm weather station (Gazeeka WeatherBox, Vomax Instrumentation Pty Ltd (), Marleston SA). Despite ambient temperatures being naturally high during the trial period (Table 1), most sheep were able to maintain their core temperature below their upper limit $\left(39.9^{\circ} \mathrm{C}\right)$, as indicated by the automated collection of vaginal temperature (Fig. 6).

Despite all data being downloaded at the conclusion of the study with $0 \%$ data loss, there is a potential for data loggers to either become dislodged or fail to collect and store data successfully, which can only be recognised during the data download period. Another limitation of indwelling loggers is that prolonged use may lead to infection or expulsion. Fortunately, the current study found little to no irritation or damage posed to vaginal tissue. VT measurement produces a reading that more closely reflects core temperature and is the most consistent with RT readings when compared to peripheral and subcutaneous sensors [22]. However, the device is a data logger not a radiotelemetry device, meaning that data are stored and must be downloaded. Radiotelemetry technology would be especially useful in an industry setting, as all data would be communicated and transcribed to a database with the ability to monitor body temperature in real-time. Nevertheless, automated data loggers are a reliable and advantageous method of obtaining accurate body temperature measurements within a research setting.

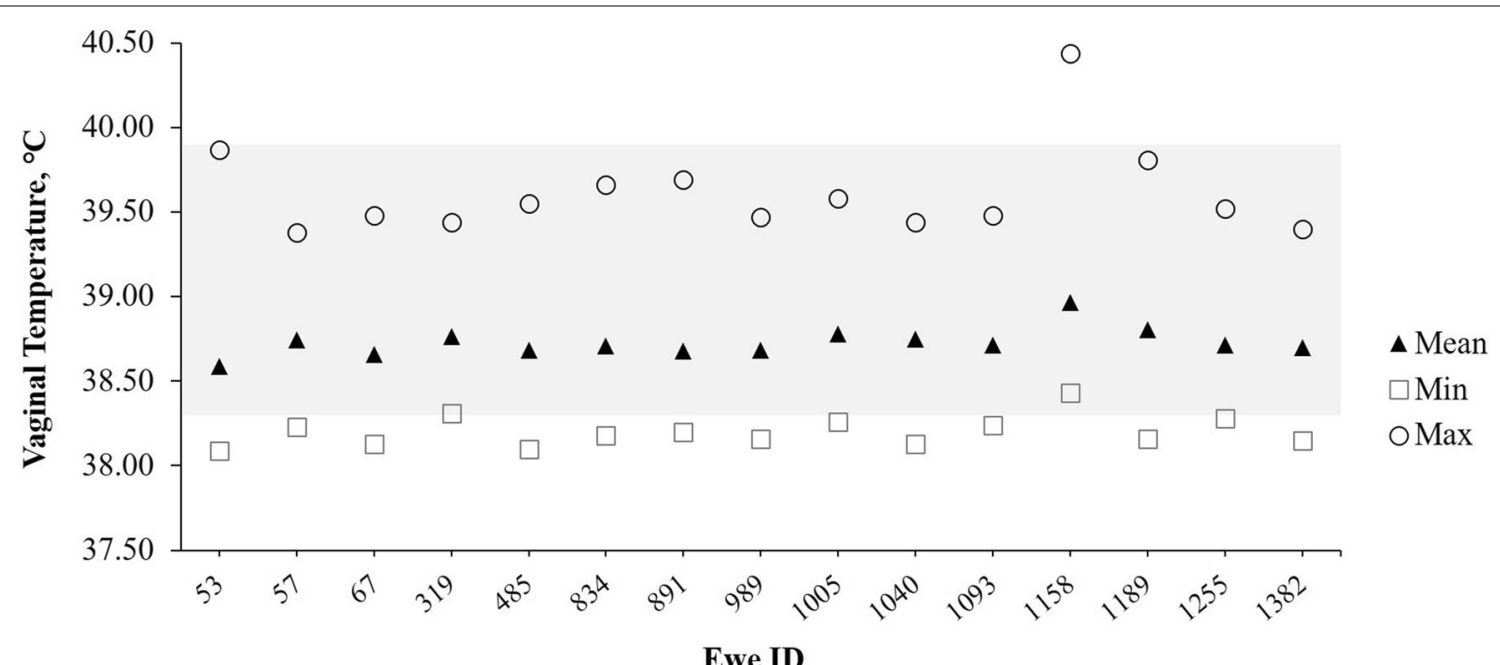

Fig. 6 Mean, minimum and maximum vaginal temperature $\left(\mathrm{VT},{ }^{\circ} \mathrm{C}\right)$ for each individual ewe during the trial period. Shaded area indicates the normal temperature range of a sheep $\left(38.3-39.9^{\circ} \mathrm{C}\right)$ [43]. Individual ewe variance for VT ranged from 0.029 to $0.056^{\circ} \mathrm{C}$ 


\section{Conclusions}

In the current study, VT and RT were found to demonstrate a moderate linear relationship, level of agreement and reproducibility. The improved deployment technique trialled in this study facilitated the accurate measurement of VT and proved to be a reliable method for the automated collection of core body temperature in dry Merino ewes. Although VT can only be measured in female animals, it is minimally invasive and considered the best site for the short-term measurement of body temperature in female sheep. A major finding in this study was the marked effect that human interference has on acute fluctuations in body temperature. Stress-induced hyperthermia is an important evolutionary mechanism and prey animals must be aware of their environment and respond properly to all kinds of stimuli. This highlights the importance of decreasing the need for human handling and restraint during the collection of physiological data, such as body temperature. Due to the ability to take continuous measurements over time without the need for a human observer, indwelling data loggers are undoubtedly more useful in a research setting and for evaluating heat stress in sheep. Future research using this automated approach, will have the ability to accurately monitor the body temperature of free-ranging ewes and quantify the impact of hot conditions on the ability of ewes to maintain their core temperature within normal range. The temperature loggers used in this study have enough sensitivity and accuracy to define the thermal thresholds of individual sheep. Identifying differences in the thermal thresholds of individual ewes could then allow investigation into the transgenerational effects of heat tolerance.

\section{Abbreviations \\ VT: Vaginal temperature; CIDR: Controlled internal drug release; RT: Rectal temperature; IRT: Infrared thermography; CNC: Computer numerical control; DST: Data storage tag; LCCC: Lin's concordance correlation coefficient; SIH: Stress-induced hyperthermia.}

\section{Acknowledgements}

The authors wish to acknowledge the support provided by academic and farm staff at the South Australian Research Development Institute (SARDI), Turretfield Research Centre.

\section{Authors' contributions}

WHEJVW, AMS, STL: conceptualisation, data curation, formal analysis, investigation, methodology, project administration, resources, supervision, validation, visualisation, writing — original draft, review and editing. AK, MB: conceptualisation, data curation, funding acquisition, investigation, methodology, resources, validation, visualisation, writing - original draft, review and editing. BELB: conceptualisation, data curation, formal analysis, investigation, methodology, resources, validation, visualisation, writing - original draft, review and editing. All authors read and approved the final manuscript.

\section{Authors' informations}

Bobbie E. Lewis Baida: Ph.D. candidate, Miss Lewis Baida, received B.Sci (Animal Behaviour) in 2015, B.Sci (Animal Science) in 2018 and high class Honours in 2019. She has since pursued her Doctor of Philosophy in Livestock Reproduction Science in 2020 at the University of Adelaide's School of Animal and
Veterinary Sciences. Her work is aimed at investigating the effects of heat stress in free-ranging sheep, more specifically, the physiological and behavioural responses of sheep maintained in hot environments and the ramifications on their productivity and reproductive success.

Alok K. Kushwaha: Dr. Kushwaha received the B.Tech degree in Electronics and Communication Engineering in 1995, M.Tech degree in Electronics and Communication Engineering in 2000 and Ph.D. degree in Microelectronics in 2011, all from the Department of Electronics and Communication Engineering, National Institute of Technology, Kurukshetra, Haryana, India. He has been into academic and research since 2000 and worked at various positions starting from lecturer to the post of professor. Currently, working with The University of Adelaide at School of Electrical and Electronic Engineering. His research interests include semiconductor devices and modelling, medical image and signal processing, antenna design and machine learning.

Mathias Baumert: Associate Professor Mathias Baumert is the Health Technology research theme leader at the School of Electrical Electronic Engineering at the University of Adelaide. He is an expert in biomedical signal processing with focus on dynamic electrocardiography and sleep research. Mathias is currently involved in studies investigating the beat-to-beat variability of ventricular repolarisation, its physiological underpinnings and clinical research applications. In addition, he explores signal processing approaches for characterising sleep related phenomena to derive diagnostic markers for sleep disordered breathing.

Alyce M. Swinbourne: Dr. Alyce Swinbourne is an early career researcher specialising in animal reproductive behaviour and physiology, with a keen interest in how reproductive hormones drive female behaviour. She has worked with both domestic and wildlife species, starting her research career investigating the nutritional impacts on oocyte development in pigs. Alyce conducted her Ph.D. on wombat reproduction through the University of Queensland's Wildlife Endocrinology Laboratory and has recently completed her Post-Doctoral Research Fellowship with the University of Adelaide investigating strategies to improve neonatal lamb survival. Alyce now works with the South Australian Research and Development Institute and remains as a research affiliate with the University of Adelaide.

Stephan T. Leu: Dr. Stephan Leu is a Lecture in Animal Behaviour at the University of Adelaide, School of Veterinary and Animal Sciences. His research focusses on social behaviour, movement ecology and disease transmission. He also has a keen interest in the effect of harsh environments, such as the Australian outback, on animal behaviour.

William van Wettere: Dr. van Wettere is a reproductive physiologist, who conducted his Ph.D. at the University of Adelaide in 2008 and has over 18 years of experience researching strategies to improve the fertility and fecundity of ewes and sows. Will's research interests focus on all aspects of sheep and pig reproduction, with particular focus on understanding the impacts of exogenous challenges, including extremes of temperature, on sheep and pig reproduction, and developing practical strategies to alleviate these impacts.

\section{Funding}

The corresponding author, BE Lewis Baida, holds a Research Training Program Stipend by the University of Adelaide and is supported by a top-up scholarship granted by the Davies Livestock Research Centre, Roseworthy, SA, Australia. Additionally, this author was the recipient of a seed grant funded by the School of Animal and Veterinary Sciences, University of Adelaide, Roseworthy Campus, SA, Australia. Lastly, senior author, ST Leu, receives funding from the Australian Research Council (ARC), Australia [DE170101132].

\section{Declarations}

\section{Competing interests}

The authors declare that they have no competing interests.

\section{Author details}

${ }^{1}$ Davies Livestock Research Centre, School of Animal and Veterinary Sciences, The University of Adelaide, Roseworthy Campus, Mudla Wirra Rd, Roseworthy, SA 5371, Australia. ${ }^{2}$ Faculty of Engineering, Computer and Mathematical Sciences, The University of Adelaide, Level 1 Ingkarni Wardli Building, North Terrace Campus, Adelaide, SA 5005, Australia. ${ }^{3}$ South Australian Research and Development Institute, Turretfield Research Centre, Rosedale, SA 5350, Australia. 
Received: 2 November 2021 Accepted: 25 January 2022

Published online: 18 February 2022

\section{References}

1. Aggarwal A, Upadhyay R. Heat stress and hormones. In: Aggarwal A Upadhyay R, editors. Heat stress and animal productivity. Berlin: Springer; 2013. p. 27-51. https://doi.org/10.1007/978-81-322-0879-2 2

2. Hopkins PS, Knights Gl, Le Feuvre AS. Studies of the environmental physiology of tropical merinos. Aust J Agric Res. 1978;29:161-71. https:// doi.org/10.1071/AR9780161.

3. Sevi A, Annicchiarico G, Albenzio M, Taibi L, Muscio A, Dell'aquila S. Effects of solar radiation and feeding time on behavior, immune response and production of lactating ewes under high ambient temperature. J Dairy Sci. 2001;84:629-40. https://doi.org/10.3168/jds.S0022-0302(01)74518-3.

4. Leu ST, Quiring K, Leggett KE, Griffith SC. Consistent behavioural responses to heatwaves provide body condition benefits in rangeland sheep. Appl Anim Behav Sci. 2021;234:105204. https://doi.org/10.1016/j. applanim.2020.105204.

5. Alhidary I, Shini S, Al Jassim R, Gaughan J. Physiological responses of Australian Merino wethers exposed to high heat load. J Anim Sci. 2012;90:212-20. https://doi.org/10.2527/jas.2011-3972.

6. Sellier N, Guettier E, Staub C. A review of methods to measure animal body temperature in precision farming. Am J Agric Sci Technol. 2014;2:74-99. https://doi.org/10.7726/ajast.2014.1008.

7. Kumar D, De K, Sejian V, Naqvi SK. Impact of climate change on sheep reproduction. In: Sejian V, Bhatta R, Gaughan J, Malik PK, Naqvi SM, Lal $R$, editors. Sheep production adapting to climate change. Singapore: Springer; 2017. p. 71-93. https://doi.org/10.1007/978-981-10-4714-5_3.

8. Macmillan K, Colazo M, Cook N. Evaluation of infrared thermography compared to rectal temperature to identify illness in early postpartum dairy cows. Res Vet Sci. 2019;125:315-22. https://doi.org/10.1016/j.rvsc. 2019.07.017.

9. Richeson JT, Powell JG, Kegley EB, Hornsby JA. Evaluation of an earmounted tympanic thermometer device for bovine respiratory disease diagnosis. Fayetteville: University of Arkanas System; 2011. https://schol arworks.uark.edu/aaesser.

10. Bouwknecht AJ, Olivier B, Paylor RE. The stress-induced hyperthermia paradigm as a physiological animal model for anxiety: a review of pharmacological and genetic studies in the mouse. Neurosci Biobehav Rev. 2007:31:41-59. https://doi.org/10.1016/j.neubiorev.2006.02.002.

11. McCafferty DJ, Gallon S, Nord A. Challenges of measuring body temperatures of free-ranging birds and mammals. Anim Biotelem. 2015:3:1-10. https://doi.org/10.1186/s40317-015-0075-2.

12. Wijffels $G$, Sullivan M, Gaughan J. Methods to quantify heat stress in ruminants: current status and future prospects. Methods. 2020;186:3-13. https://doi.org/10.1016/j.ymeth.2020.09.004.

13. Lewis Baida BE, Swinbourne AM, Barwick J, Leu ST, van Wettere WH. Technologies for the automated collection of heat stress data in sheep. Anim Biotelem. 2021:9:1-15. https://doi.org/10.1186/s40317-020-00225-9.

14. Beatty DT, Barnes A, Fleming PA, Taylor E, Maloney SK. The effect of fleece on core and rumen temperature in sheep. J Therm Biol. 2008:33:437-43. https://doi.org/10.1016/j.jtherbio.2008.07.002.

15. Abecia JA, Pascual-Alonso M, Aguayo-Ulloa LA, Maria GA. Comparison of several devices to measure body temperature in sheep. Precis Livest Farm. 2015;221-9.

16. Boehmer BH, Pye TA, Wettemann RP. Ruminal temperature as a measure of body temperature of beef cows and relationship with ambient temperature. Prof Anim Sci. 2015;31:387-93. https://doi.org/10.15232/pas. 2014-01336.

17. McManus CM, Bianchini E, Paim TDP, De Lima FG, Neto JB, Castanheira M, Esteves GIF, Cardoso CC, Dalcin VC. Infrared thermography to evaluate heat tolerance in different genetic groups of lambs. Sensors. 2015;15:17258-73. https://doi.org/10.3390/s150717258.

18. Soerensen DD, Pedersen $L$. Infrared skin temperature measurements for monitoring health in pigs: a review. Acta Vet Scand. 2015;57:1-11. https:// doi.org/10.1186/s13028-015-0094-2.

19. Koltes JE, Koltes DA, Mote BE, Tucker J, Hubbell DS. Automated collection of heat stress data in livestock: new technologies and opportunities Transl Anim Sci. 2018;2:319-23. https://doi.org/10.1093/tas/txy061.
20. George WD, Godfrey RW, Ketring RC, Vinson MC, Willard ST. Relationship among eye and muzzle temperatures measured using digital infrared thermal imaging and vaginal and rectal temperatures in hair sheep and cattle. J Anim Sci. 2014;92:4949-55. https://doi.org/10.2527/jas. 2014-8087.

21. Pent GJ, Fike JH, Kim I. Ewe lamb vaginal temperatures in hardwood silvopastures. Agrofor Syst. 2018. https://doi.org/10.1007/ s10457-018-0221-y.

22. Kearton TR, Doughty AK, Morton CL, Hinch GN, Godwin IR, Cowley FC. Core and peripheral site measurement of body temperature in short wool sheep. J Therm Biol. 2020;90:102606-14. https://doi.org/10.1016/j. jtherbio.2020.102606

23. Reuter RR, Carroll JA, Hulbert LE, Dailey JW, Galyean ML. Technical note: Development of a self-contained, indwelling rectal temperature probe for cattle research. J Anim Sci. 2010;88:3291-5. https://doi.org/10.2527/ jas.2010-3093.

24. Godfrey RW, Preston WD, Joseph SR, LaPlace L, Hillman PE, Gebremedhin KG, Lee CN, Collier RJ. Evaluating the impact of breed, pregnancy, and hair coat on body temperature and sweating rate of hair sheep ewes in the tropics 1. J Anim Sci. 2017;95:2936-42. https://doi.org/10.2527/jas. 2016.1125 .

25. Suthar V, Burfeind O, Maeder B, Heuwieser W. Agreement between rectal and vaginal temperature measured with temperature loggers in dairy cows. J Dairy Res. 2013;80:240-5. https://doi.org/10.1017/S002202991 3000071.

26. Tresoldi G, Schütz KE, Tucker CB. Sampling strategy and measurement device affect vaginal temperature outcomes in lactating dairy cattle. J Dairy Sci. 2020. https://doi.org/10.3168/jds.2019-16667.

27. Burdick NC, Carroll JA, Dailey JW, Randel RD, Falkenberg SM, Schmidt TB. Development of a self-contained, indwelling vaginal temperature probe for use in cattle research. J Therm Biol. 2012;37:339-43. https://doi.org/10 1016/j.jtherbio.2011.10.007.

28. Snyder S, Franks PJ. Quantifying the effects of sensor coatings on body temperature measurements. Anim Biotelem. 2016:4:1-9. https://doi.org/ 10.1186/s40317-016-0100-0.

29. Zoetis. Eazi-breed cidr (progesterone intravaginal insert) sheep insert 2018. https://www.zoetisus.com/contact/pages/product_information/ msds_pi/pi/eazi-breed_cidr_sheep.pdf. Accessed 25 May 2021.

30. Bland JM, Altman DG. Statistical methods for assessing agreement between two methods of clinical measurement. Lancet. 1986:327:30710. https://doi.org/10.1016/S0140-6736(86)90837-8.

31. Lin LK. A concordance correlation coefficient to evaluate reproducibility. Biometrics. 1989. https://doi.org/10.2307/2532051.

32. Dwyer C. How has the risk of predation shaped the behavioural responses of sheep to fear and distress? Anim Welf. 2004;13:269-81.

33. Lees AM, Lea JM, Salvin HE, Cafe LM, Colditz IG, Lee C. Relationship between rectal temperature and vaginal temperature in grazing Bos Taurus heifers. Animals. 2018;8:156-64. https://doi.org/10.3390/ani8090156.

34. Vickers LA, Burfeind $O$, von Keyserlingk MA, Veira DM, Weary DM, Heuwieser W. Technical note: Comparison of rectal and vaginal temperatures in lactating dairy cows. J Dairy Sci. 2010:93:5246-51. https://doi.org/10. 3168/jds.2010-3388

35. Sanger ME, Doyle RE, Hinch GN, Lee C. Sheep exhibit a positive judgement bias and stress-induced hyperthermia following shearing. Appl Anim Behav Sci. 2011;131:94-103. https://doi.org/10.1016/j.applanim. 2011.02.001.

36. Ingram J, Cook C, Harris P. The effect of transport on core and peripheral body temperatures and heart rate of sheep. Anim Welf. 2002;11:103-12.

37. Lowe TE, Cook CJ, Ingram JR, Harris PJ. Impact of climate on thermal rhythm in pastoral sheep. Physiol Behav. 2001;74:659-64. https://doi.org/ 10.1016/S0031-9384(01)00608-4.

38. Australian Livestock Export Corporation Ltd. Heat stress risk assessment for export of sheep to the Middle East. 2019. https://www.agriculture.gov. au/sites/default/files/documents/hsra-draft-livecorp.pdf.

39. Srikandakumar A, Johnson EH, Mahgoub O. Effect of heat stress on respiratory rate, rectal temperature and blood chemistry in Omani and Australian Merino sheep. Small Rumin Res. 2003;49:193-8. https://doi org/10.1016/s0921-4488(03)00097-x.

40. Emmanuel AV, Kamm MA, Beard RW. Reproducible assessment of vaginal and rectal mucosal and skin blood flow: Laser Doppler fluximetry of the 
pelvic microcirculation. Clin Sci. 2000;98:201-7. https://doi.org/10.1042/ cs0980201.

41. Giavarina D. Understanding Bland Altman analysis. Biochem Med. 2015;25:141-51. https://doi.org/10.11613/BM.2015.015

42. Bland JM, Altman DG. Measuring agreement in method comparison studies. Stat Methods Med Res. 1999;8:135-60. https://doi.org/10.1177/ 096228029900800204.

43. Fielder S. Normal ranges. 2019. https://www.merckvetmanual.com/Searc hResults?query=Normal+ranges.

44. Akoglu H. User's guide to correlation coefficients. Turk J Emerg Med. 2018;18:91-3. https://doi.org/10.1016/j.tjem.2018.08.001

45. Altman DG. Practical statistics for medical research. Boca Raton: CRC Press; 1990.

46. McBride G. A proposal for strength-of-agreement criteria for Lin's concordance correlation coefficient. 2005.

47. Liao J. An improved concordance correlation coefficient. J Appl Stat. 2003;2:253-61. https://doi.org/10.1002/pst.52.

48. Landis JR, Koch GG. The measurement of observer agreement for categorical data. Biometrics. 1977;33:159-74.

49. Refinetti $R$, Menaker $M$. The circadian rhythm of body temperature. Physiol Behav. 1992;51:613-37. https://doi.org/10.1016/0031-9384(92) 90188-8.

50. Lees AM, Lees JC, Lisle AT, Sullivan ML, Gaughan JB. Effect of heat stress on rumen temperature of three breeds of cattle. Int J Biometeorol. 2018;62:207-15. https://doi.org/10.1007/s00484-017-1442-x.

\section{Publisher's Note}

Springer Nature remains neutral with regard to jurisdictional claims in published maps and institutional affiliations.

- fast, convenient online submission

- thorough peer review by experienced researchers in your field

- rapid publication on acceptance

- support for research data, including large and complex data types

- gold Open Access which fosters wider collaboration and increased citations

- maximum visibility for your research: over $100 \mathrm{M}$ website views per year

At BMC, research is always in progress.

Learn more biomedcentral.com/submissions 